\title{
ANALYSIS OF CORONA DISCHARGE IN ELECTROSTATIC MOTOR GAPS
}

\author{
Mazen Abdel-Salam, Adel Ahmed, Hamdy Ziedan and Fahd Diab *
}

Electrical Engineering Department, Assiut University, Assiut, Egypt.

Received 5 June 2013; accepted 20 July 2013

\begin{abstract}
This paper is aimed at calculating corona current-voltage characteristics of a new design of an electrostatic motor with a cylindrical rotor made from aluminium foil and multi stator copper electrodes. The stator electrodes are alternately stressed positively and negatively. The corona currents emitted from positively and negatively-stressed electrodes are calculated being dependent on the applied voltage and motor geometry. The method of calculation is based on simultaneous solution of Poisson's equation, current density equation and continuity equation for current density. This calls at first for calculation of the spatial distribution of electric field within the motor volume using the accurate charge simulation technique. The calculated current-voltage characteristics of the motor agreed reasonably with those measured experimentally for three motors built-in the laboratory.
\end{abstract}

Keywords: Electrostatic motor, corona-discharge, electric field, corona current.

\section{Introduction}

\section{1. Previous related work}

Historically speaking, the first electric motor invented was a corona-based electrostatic motor (ESM) and it was about 100 years before the conventional magnetic motor was conceived[1]. The ESM is characterised by simplicity of construction without winding and light weight. The influence of corona electrodes' configurations on output torque was experimentally investigated in ESM with multi-blade electrodes[1]. The motor fabricated consisted of a $100 \mathrm{~mm}$ diameter hollow cylindrical rotor made of acrylic resin as a dielectric and several knife-blade corona electrodes with $100 \mathrm{~mm}$ length[1].

A micro ESM was fabricated [2] with sharp stator electrodes to ionize air molecules. The ions are transferred onto the rotor surface where coulomb repulsion between insulated rotor and electrodes result in a rotation of the rotor. Important design parameters, such as electrode spacing, air gap, and number of electrodes were studied [2] using an electrostatic field simulator. For good performance, the stator's electrodes should be axially thick with sharp tips[2]. Speed and torque were measured where the torque was estimated in the order of $10 \mathrm{nNm}[2]$.

Corona motors are of interest in minature applications because of their insensitivity to material properties and their ability to produce torque with DC excitation [3].

\section{2. Aim of paper}

This paper is aimed at calculating corona current-voltage characteristics of a new design of an electrostatic motor with conducting cylindrical rotor and multi-stator electrodes. The current-voltage characteristics are calculated and checked against those measured

\footnotetext{
* Corresponding author.

E-mail address: fahd.maoad@yahoo.com
} 
Fahd Diab et al., Analysis of Corona Discharge in Electrostatic Motor Gaps, pp. 1842 - 1856

experimentally for built-in laboratory motor models. This calls at first for field calculation using the accurate charge simulation method.

\section{The Proposed ESM}

The proposed ESM has a cylindrical rotor of radius $\mathrm{R}$ made of aluminum foil which rotates on the tip of a metal shaft having very small contact area so the friction loss is very small. The stator electrodes are strips capped with wedge at the tip, made from copper and insulated by cylindrical wooden shell of inner and outer radii R1 and R2, respectively, as shown in figure 1 . The height of the wedge is $h$ and that of the electrode is $H$. The gap spacing between the stator tip and the rotor surface is g. For two-dimensional analysis, the motor is assumed long enough when compared with the dimensions of the stator.

The principle of operation of the proposed ESM depends on the "Ionic Wind" phenomena [4-11]. Positive and negative high voltages are applied to the stator electrodes alternately. Subsequently, a strong electric field is generated near the electrodes to form a corona discharge in air at electrodes' tips. The air motion is created by the corona ions generated at the electrodes, which drift either to the grounded rotor or to the nearby (surrounding) electrodes. Along their path, these ions collide with the electrically neutral air, transferring their momentum to air molecules resulting in the so-called "electric or ionic wind" [4-11]. Therefore, the ionic wind in this motor consists of two components: The first component is the monopolar component, which is directed from the high voltage electrode toward the grounded rotor. This component is normal to the rotor surface and doesn't contribute to motor rotation. The second component is the bipolar one, which extends between the positive and negative electrodes tangentially with respect to the rotor surface. This component is responsible for motor rotation. An electrode tilting is aimed at enhancing the developed torque to run the rotor of the ESM.

\section{Method of Analysis}

Due to the alternative polarity of the electrodes there are two components of corona current:

1. Monopolar component.

2. Bipolar component.

\section{1. Calculation of monopolar corona current component}

The monopolar component of corona current is convected between each stator electrode and the grounded rotor.

Journal of Engineering Sciences, Assiut University, Faculty of Engineering, Vol. 41, No. 5, September, 2013, E-mail address: jes@aun.edu.eg 


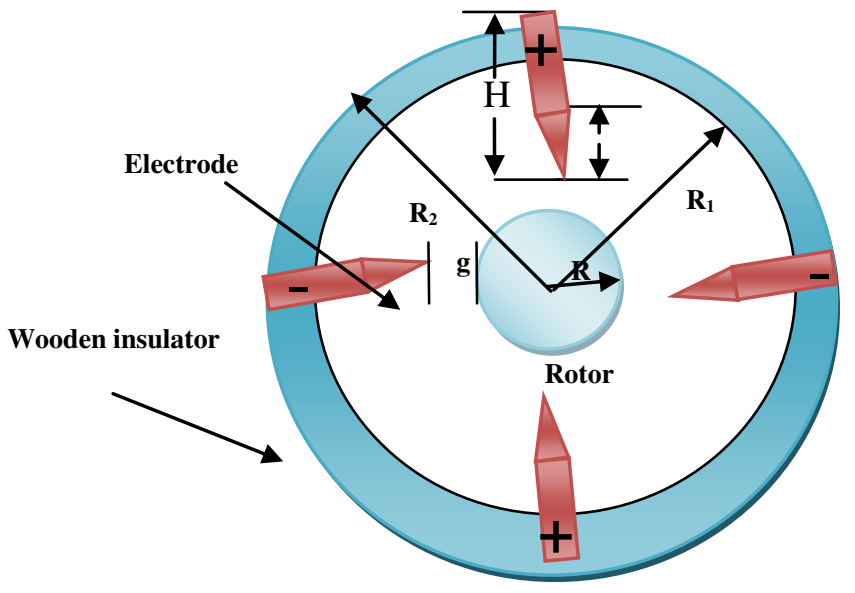

Fig. 1. Cross section of the proposed 4-electrode ESM

\section{1. 1. Describing equations}

Based on Deutsch's assumption [12], the electric field E in the presence of space charge and the space-charge-free field $\mathrm{E}^{\prime}$ are related as

$\mathrm{E}=\xi \mathrm{E}^{\prime}$

where

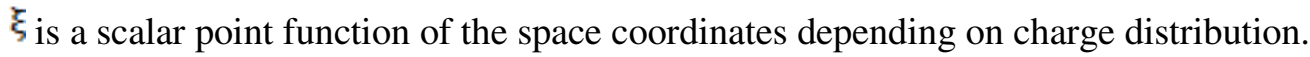

The equations describing the electric field and the ionic flow are

$\nabla E=\frac{p}{\epsilon_{0}}$

$\mathrm{J}=\mathrm{K} \rho \mathrm{E}$

$\nabla \mathrm{J}=0$

where

$\rho \quad$ is the volume space-charge density $(\mathrm{C} / \mathrm{m} 3)$.

$\in \mathrm{O} \quad$ is permittivity of free space $(=(1 / 36 \pi) \times 10-9(\mathrm{~F} / \mathrm{m}))$.

$\mathrm{K}$ is the mobility of ions $(=1.5 \times 10-4(\mathrm{~m} 2 / \mathrm{V} . \mathrm{s}))$.

I is the current density $(\mathrm{A} / \mathrm{m} 2)$.

The first is Poisson's equation for the electric field, the second is the equation for current density, and the third is the equation of current continuity. Thermal diffusion of ions is neglected.

\section{1. 2. Boundary conditions}

\section{1. 2. 1. Boundary conditions at the electrodes}

Voltage without space charge $\varphi= \pm \mathrm{V}$.

Voltage with space charge $\Phi= \pm \mathrm{V}$.

Journal of Engineering Sciences, Assiut University, Faculty of Engineering, Vol. 41, No. 5, September, 2013, E-mail address: jes@aun.edu.eg 
The ratio $\frac{\mathrm{E}}{\mathrm{E}^{r}}$ is $\xi_{\mathrm{e}}=\left(\frac{V_{\mathrm{O}}}{\mathrm{V}}\right)$

\section{1. 2. 2. Boundary conditions at rotor surface}

Voltage without space charge $\varphi=0$.

Voltage with space charge $\Phi=0$.

Mathematical manipulation of equations (1) througth (4) results in the following expressions which determine distribution of the ion charge density $\rho$ and the scalar $\xi$ along the field lines emanating from stator electrodes to the grounded rotor.

$$
\begin{aligned}
& \left(\frac{1}{\mathrm{p}^{2}}\right)=\left(\frac{1}{\rho_{\mathrm{\rho}}^{2}}\right)+\left(\frac{2}{\epsilon_{0} \rho_{\mathrm{e}} \xi_{\mathrm{e}}}\right) \int_{\varphi}^{v} d \varphi /\left(E^{\prime}\right) \\
& \xi^{2}=\xi_{\mathrm{e}}^{2}+\left(\frac{\rho_{\mathrm{e}} \xi_{\mathrm{e}}}{\mathrm{E}_{\mathrm{0}}}\right) \int_{\varphi}^{v} d \varphi /\left(E^{\prime}\right)
\end{aligned}
$$

where

pe is the volume space-charge density at the electrode surface $(\mathrm{C} / \mathrm{m} 3)$.

Equations (5) and (6) are to be integrated along the electric field lines which extend from the corona electrodes to the grounded rotor. An iterative procedure was proposed before [12] to determine the charge density $\rho$ e at the corona electrode surface.

After convergence, one can calculate the monopolar current density where a field line emanates from the stator electrode surface to the grounded rotor as:

$$
\mathrm{I}_{\text {monopolar } \pm=} \mathrm{K}_{ \pm} \rho_{\mathrm{e}} \mathrm{E}_{\text {gmono. }}
$$

where

$\mathrm{E}_{\text {smona }}$ is the electric field at electrode surface, where monopolar corona takes place. The mobility value of ions is chosen depending on the polarity of the electrode.

The monopolar corona current conducted through a flux tube, whose axis is the field line, is obtained as:

$$
I_{\text {monopolar tube } \pm=} I_{\text {monopolar } \pm} \Delta S
$$

where $\Delta \mathrm{S}$ is the longitudinal normal surface area of the flux tube.

The monopolar corona current per positive or negative electrode is obtained as:

$$
I_{\text {monopolar elec } \pm=\sum} I_{\text {monopolar tubet }}
$$

where the summation takes place over all flux tubes along them the monopolar corona ions convect around the surface of stator electrode.

The motor monopolar corona current is obtained by summing the current emitted from all electrodes as:

$I_{\text {monopolar motor }}=\sum_{\text {No.of pairs elec, }}\left(I_{\text {monopolar elecpos, }}+I_{\text {monopolar elecneg. }}\right)$

where the number of positively-stressed electrodes is equal to that of the negativelystressed electrodes.

Journal of Engineering Sciences, Assiut University, Faculty of Engineering, Vol. 41, No. 5, September, 2013, E-mail address: jes@aun.edu.eg 


\section{2. Calculation of bipolar corona current component}

The bipolar component of corona current is convected between neighboring electrodes. To calculate the bipolar component of current, the idealized model proposed before [13] is adopted. In the idealized model, symmetry around the zero potential plane between two successive electrodes is considered. The zero potential plane is considered as one of the boundaries in solving the equations of the ionized field. The boundary value problem therefore be solved only between $\varphi=0$ and $\varphi=\mathrm{V}$ instead of between $\varphi=-\mathrm{V}$ and $\varphi=\mathrm{V}$ at both positive and negative electrodes.

\section{2. 1. Describing equations}

These equations are based on assuming equal mobility of both positive and negative ions and equal corona onset voltage at both the positive and negative electrodes $(\mathrm{Vo}+=\mathrm{Vo}-=$ Vo).

$$
\begin{aligned}
& \frac{\mathrm{d} \Phi}{\mathrm{d} \varphi}=\xi \\
& \frac{\mathrm{d} \rho_{+}}{\mathrm{d} \varphi}=\rho+(\rho+-\mathrm{C} 1 \rho-) /\left(\in \mathrm{O} \xi \mathrm{E}^{\prime} 2\right) \\
& \frac{\mathrm{d} \rho_{-}}{\mathrm{d} \varphi}=-\rho-(\rho--\mathrm{C} 1 \rho+) /\left(\in \mathrm{O} \xi^{\prime} 2\right) \\
& \frac{\mathrm{d} \xi}{\mathrm{d} \varphi}=-(\rho+-\rho-) /\left(\in \mathrm{O} \mathrm{E}^{\prime} 2\right) \\
& \mathrm{C} 1=1-(\in \mathrm{O} \mathrm{Ri} / \mathrm{Ke})
\end{aligned}
$$

where

$\rho^{+} \quad$ is the volume space-charge density of positive ions $(\mathrm{C} / \mathrm{m} 3)$.

$\rho-\quad$ is the volume space-charge density of negative ions $(\mathrm{C} / \mathrm{m} 3)$.

$\mathrm{Ri}$ is the recombination coefficient of the positive and negative ions, $\mathrm{Ri}=2.2 \times 10-12$

e $(\mathrm{m} 3 / \mathrm{s})$.

$\mathrm{K}+\quad$ is the electron charge, $\mathrm{e}=1.6 \times 10-19(\mathrm{C})$.

$\mathrm{K}-\quad$ is the mobility of positive ions (m2/V.s).

$\mathrm{Vo}+$ is the mobility of negative ions ( $\mathrm{m} 2 / \mathrm{V} . \mathrm{s})$.

Vo- is the positive corona onset voltage $(\mathrm{V})$.

$\mathrm{K}+=$ is the negative corona onset voltage $(\mathrm{V})$.

$$
\mathrm{K}-=\mathrm{K}=1.5 \times 10-4 \text { (m2/V.s). }
$$

\section{2. 2. Boundary conditions}

The boundary conditions at the electrodes and rotor surfaces are the same as those for the monopolar corona current component.

Symmetry in the idealized model dictates that the volume charge density at the zero potential is expressed to the surrounding electrodes as:

$$
\rho_{+}=\rho_{-}=\rho_{0}
$$

Integrating equations (11) through (15) along the electric field lines starting from zero potential plane (midway between the positive and negative electrodes) determines the 
distribution of the ion charge density $\rho$ and the scalar $\xi$ using the iterative procedure proposed before [13].

After convergence, one can calculate the bipolar current density where a field line emanates from the stator electrode surface as:

J bipolar $\pm=K_{+} \rho_{+} E_{s b i+} K_{-} \rho_{-} E_{s b i}$

where

$\mathrm{E}_{\text {sbi. }}$ is the electric field at the electrode surface, where bipolar corona takes place.

The bipolar corona current conducted through a flux tube whose axis is the field line, is obtained as:

$$
\mathrm{I}_{\text {bipolar tube } \pm=} \mathrm{J}_{\text {bipolar } \pm} \Delta \mathrm{S}
$$

The bipolar corona current per electrode is obtained as:

$$
\mathrm{I}_{\text {bipolar elec } \pm=\sum} \mathrm{I}_{\text {bipolartube } \pm}
$$

where the summation takes place over all flux tubes, along them the bipolar corona ions convect around the surface of stator electrode.

The motor bipolar corona current is obtained as:

$$
\mathrm{I}_{\text {bipolar motor }}=\sum_{\text {No.of elec }} \mathrm{I}_{\text {bipolar elec } \pm} \pm
$$

The motor total corona current is obtained as:

$$
\mathrm{I}_{\text {motor }}=\sum\left(\mathrm{I}_{\text {momopolarmotor }}+\mathrm{I}_{\text {bipolarmotor }}\right)
$$

\section{Electric Field Calculation}

Integrating the describing equations for monopolar and bipolar coronas along the field lines is requested to determine the current-voltage characteristics of the ESM. Therefore, the field around the stator electrodes is mapped. Some field lines emanating from the electrode terminate at the grounded rotor. Along these field lines, the corona ions convect from the stressed electrode to the grounded rotor forming the monopolar component of the corona current. Other field lines emanating from the electrode terminate at the neighboring electrodes with opposite polarity. Along these field lines positive and negative ions convect forming the bipolar component of the corona current.

The charge simulation technique [14-16] is used to map the electric field lines which emanate from the stressed electrodes. As the ESM is assumed infinitely long in the Z axialdirection, infinite line charges extending parallel to the motor axis were used to simulate the conducting stator electrodes and cylindrical rotor. Each electrode is symmetrical about its axial midway plane, so the surface charges on each side of the electrode are the same. The surface charge on each side of the stator electrode is simulated by $n 1$ line charges for the electrode tip, n2 line charges for the wedge side, n3 line charges for the strip side and $\mathrm{n} 4$ line charges for the electrode base, figure 2(a). These charges are positioned inside the electrode. Thus, the number of simulation charges per electrode is $2(n 1+n 2+n 3+n 4)$ as shown in figure 2(a). The surface charge on the rotor is simulated by a number n5 line charges distributed uniformly inside the rotor as shown in figure 2(b). The surface charge

Journal of Engineering Sciences, Assiut University, Faculty of Engineering, Vol. 41, No. 5, September, 2013,E-mail address: jes@aun.edu.eg 
Fahd Diab et al., Analysis of Corona Discharge in Electrostatic Motor Gaps, pp. 1842 - 1856

on the wooden insulating material between two successive electrodes is simulated by four sets of line charges each of $n 6$ line charges. Two sets are positioned inside the dielectric and the other two sets in air as shown in figure 2(c). To evaluate the simulation charges, boundary points are selected on the surface of the stator electrodes and the rotor, where a boundary point is assigned to a simulation charge of the stator electrodes and rotor. Other boundary points are chosen on the wooden insulator surface, where a boundary point is assigned to two simulation charges. The location of line charges takes place according to assignment factor $\mathrm{Fa}=\mathrm{a} 2 / \mathrm{a} 1$ [15], where a1 is the distance between two successive boundary points and 2 is the distance between the boundary point and the corresponding simulation charge. Therefore, the total number $\mathrm{N}$ of unknowns simulation charges is: $2 n e(n 1+n 2+n 3+n 4)+n 5+4 n e n 6$ where ne is the number of stator electrodes.

The boundary conditions are:(i) The calculated potential at the boundary points selected on the stator electrodes is equal to the applied voltage. (ii) The calculated potential at the boundary points selected on the rotor surface is equal to zero. (iii) The calculated potential at the boundary points selected on the insulator surface is the same whether seen from the air or insulator sides. (iv) The continuity of the electric flux at the boundary points selected on the insulator surface is satisfied. Satisfaction of the boundary conditions at the electrodes, rotor and insulator surfaces results in a set of simultanous equations whose solution determine the unknown simulation charges. Once the simulation charges are known, one can evaluate the spatial distribution of the electric field and trace the field lines emanating from the stressed electrodes.

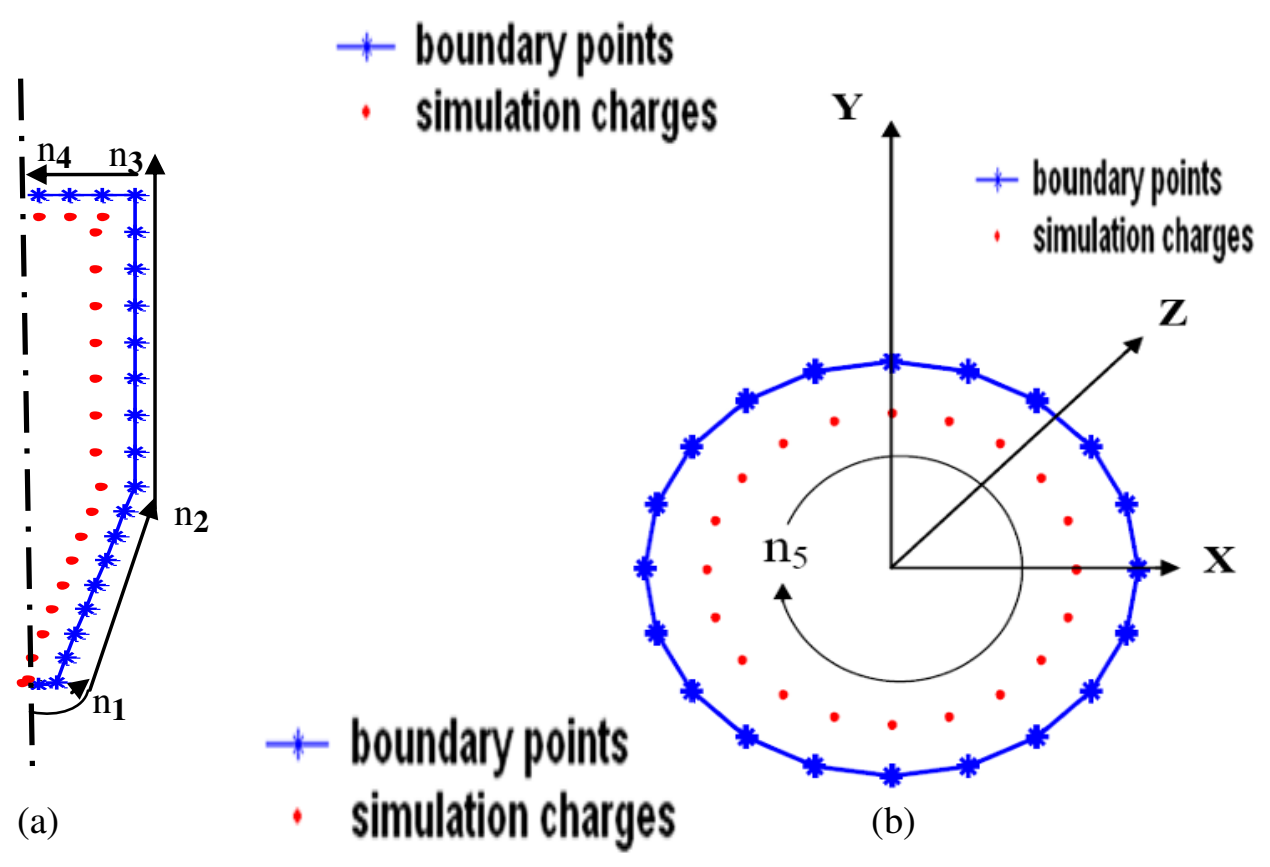

Journal of Engineering Sciences, Assiut University, Faculty of Engineering, Vol. 41, No. 5, September, 2013, E-mail address: jes@aun.edu.eg 


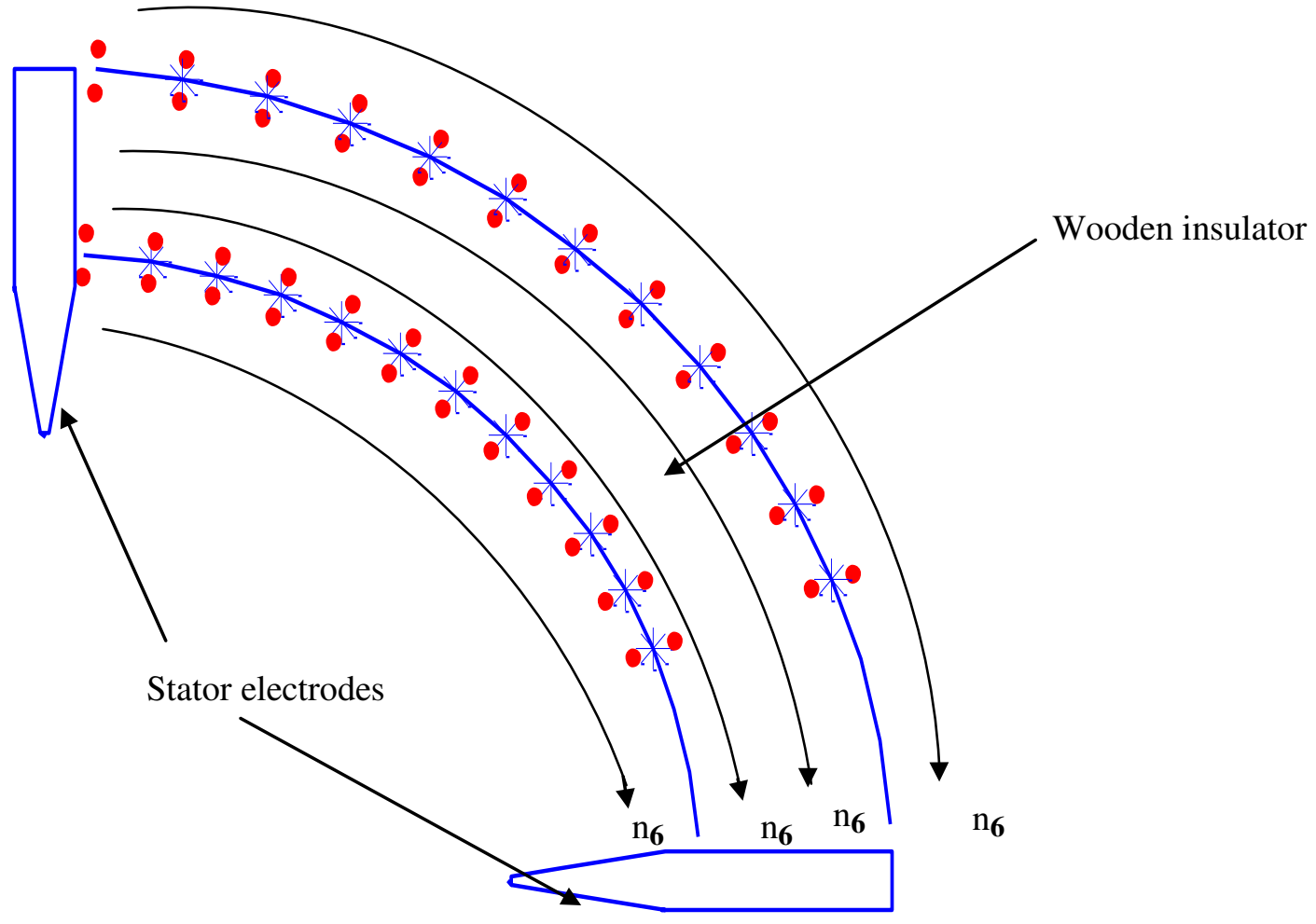

(c)

Fig. 2.(a) Cross-section of one electrode showing simulation charges and associated boundary points. (b) Cross-section of the rotor showing simulation charges and associated boundary points.(c) Cross-section of the wooden insulator between two stator electrodes showing singulation charges and associated boundary points.

\section{Experimental Setup}

The proposed ESM has a cross-sectional view as shown in figure 1. The setup to test the proposed ESM was built-in the high voltage laboratory of Assiut University. Dimensions of the proposed ESM models are given in table 1, where the sum of the rotor radius $\mathrm{R}$ and the gap spacing $\mathrm{g}$ is constant $(\mathrm{R}+\mathrm{g}=0.06 \mathrm{~m})$.

\section{Table 1.}

Dimensions of the proposed ESM.

\begin{tabular}{|c|c|c|c|c|c|c|}
\hline ESM\# & $\mathrm{R}_{1}(\mathrm{~m})$ & $\mathrm{R}_{2}(\mathrm{~m})$ & $\mathrm{R}(\mathrm{m})$ & $\mathrm{g}(\mathrm{m})$ & $\mathrm{h}(\mathrm{m})$ & $\mathrm{H}(\mathrm{m})$ \\
\hline 1 & 0.09 & 0.11 & 0.02 & 0.04 & 0.02 & 0.05 \\
\hline 2 & 0.09 & 0.11 & 0.025 & 0.035 & 0.02 & 0.05 \\
\hline 3 & 0.09 & 0.11 & 0.035 & 0.025 & 0.02 & 0.05 \\
\hline
\end{tabular}

The set-up consists of:

(1) Auto transformer with input $220 \mathrm{~V} \mathrm{AC}$, and variable output voltage from 0 to $220 \mathrm{~V}$.

Journal of Engineering Sciences, Assiut University, Faculty of Engineering, Vol. 41, No. 5, September, 2013,E-mail address: jes@aun.edu.eg 
Fahd Diab et al., Analysis of Corona Discharge in Electrostatic Motor Gaps, pp. 1842 - 1856

(2) HV transformer steps the voltage up to the desired value in the range from $0-100 \mathrm{kV}$.

(3) Half-wave positive and negative high-voltage rectifier circuit composed of two 20 $\mathrm{mA}, 140 \mathrm{kV}$ PIV diodes and $10 \mathrm{nF}, 140 \mathrm{kV}$ smoothing capacitor.

The DC voltage is applied across a $280 \mathrm{M} \Omega$ resistance in series with a micro-ammeter for measuring the generated DC voltage. Positive and negative voltages are applied alternately to the ESM electrodes through $0.5 \mathrm{M} \Omega$ water resistance to limit the current in case of a flashover occurs. The corona current was measured using sensitive microammeter connected to the stressed electrodes. Five measured readings of corona current value were recorded at the same applied voltage. A Faraday cage was built-in to accommodate the micro-ammeter, thus shielding it to ensure no corona discharge on its hardware as shown in figure $3(\mathrm{a})$.

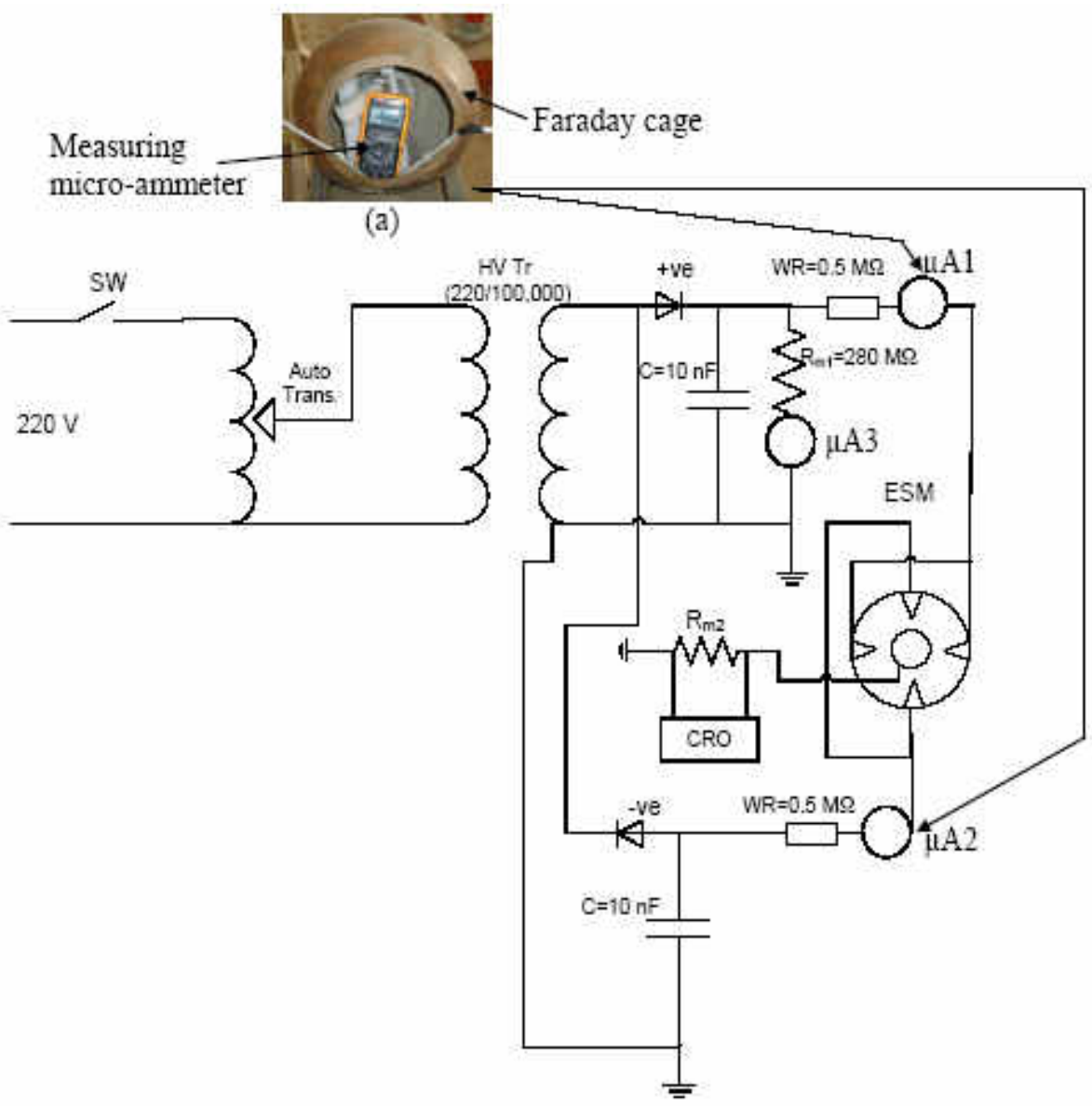

(b)

Fig. 3. (a) Faraday cage to shield the digital micro-ammeter.

(b) Schematic diagram of experimental model of ESM.

Journal of Engineering Sciences, Assiut University, Faculty of Engineering, Vol. 41, No. 5, September, 2013,E-mail address: jes@aun.edu.eg 
Fahd Diab et al., Analysis of Corona Discharge in Electrostatic Motor Gaps, pp. 1842 - 1856

\section{Results and Discussions}

6. 1. Corona current as influenced by number of stator electrodes

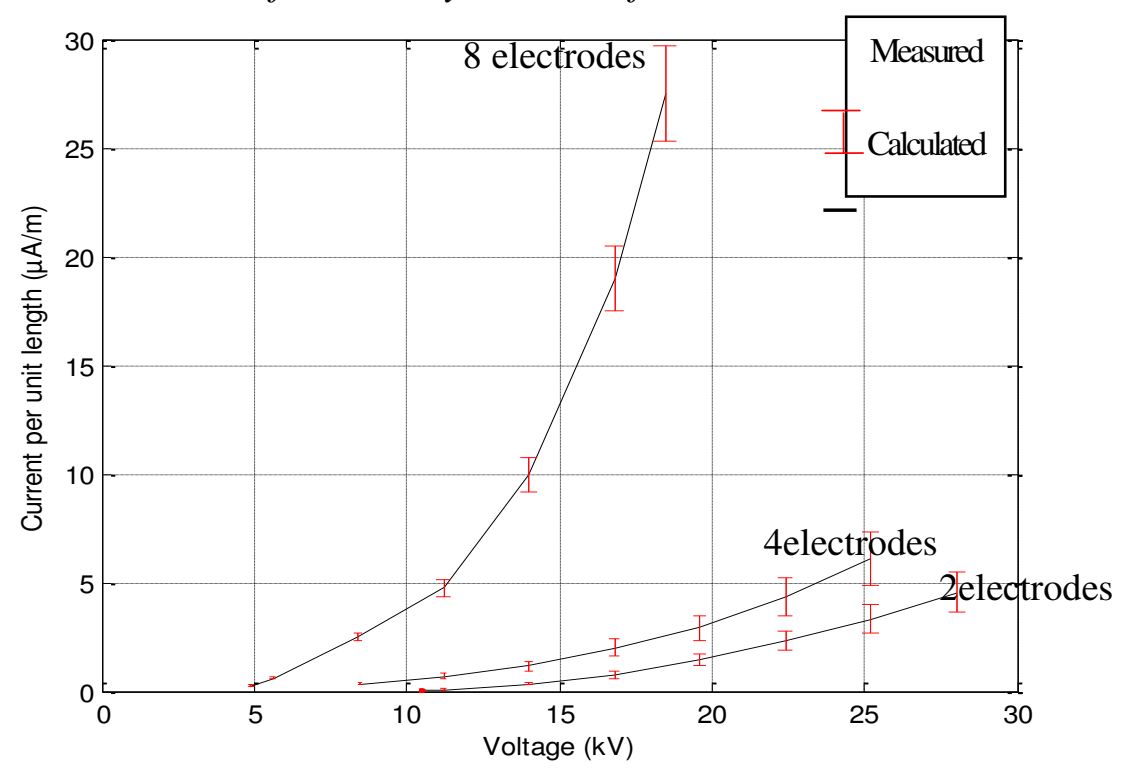

Fig. 4. Measured and calculated corona current of different number of stator electrodes $\quad(\mathrm{g}=0.04(\mathrm{~m})$ and $\mathrm{R}=0.02(\mathrm{~m})) \mathrm{ESM}$

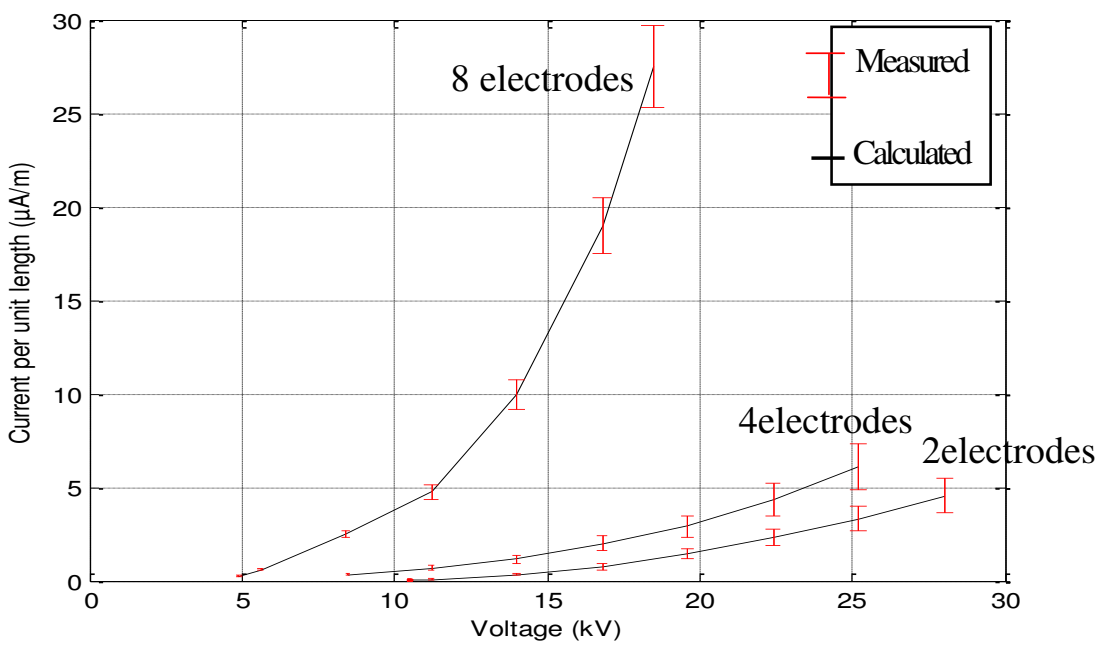

Fig. 5. Measured and calculated corona current of different number of stator electrodes $(\mathrm{g}=0.035(\mathrm{~m})$ and $\mathrm{R}=0.025(\mathrm{~m})) \mathrm{ESM}$

Journal of Engineering Sciences, Assiut University, Faculty of Engineering, Vol. 41, No. 5, September, 2013,E-mail address: jes@aun.edu.eg 


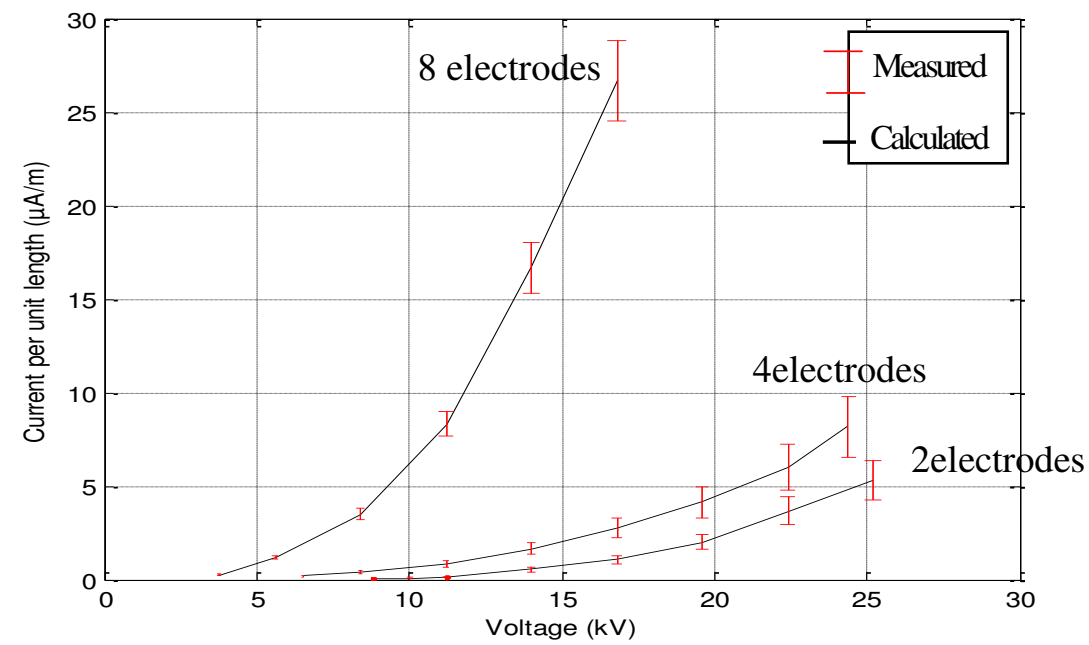

Fig. 6. Measured and calculated corona current of different number of stator electrodes $(\mathrm{g}=0.025(\mathrm{~m})$ and $\mathrm{R}=0.035(\mathrm{~m})) \mathrm{ESM}$.

\subsection{Corona current as influenced by the gap spacing}

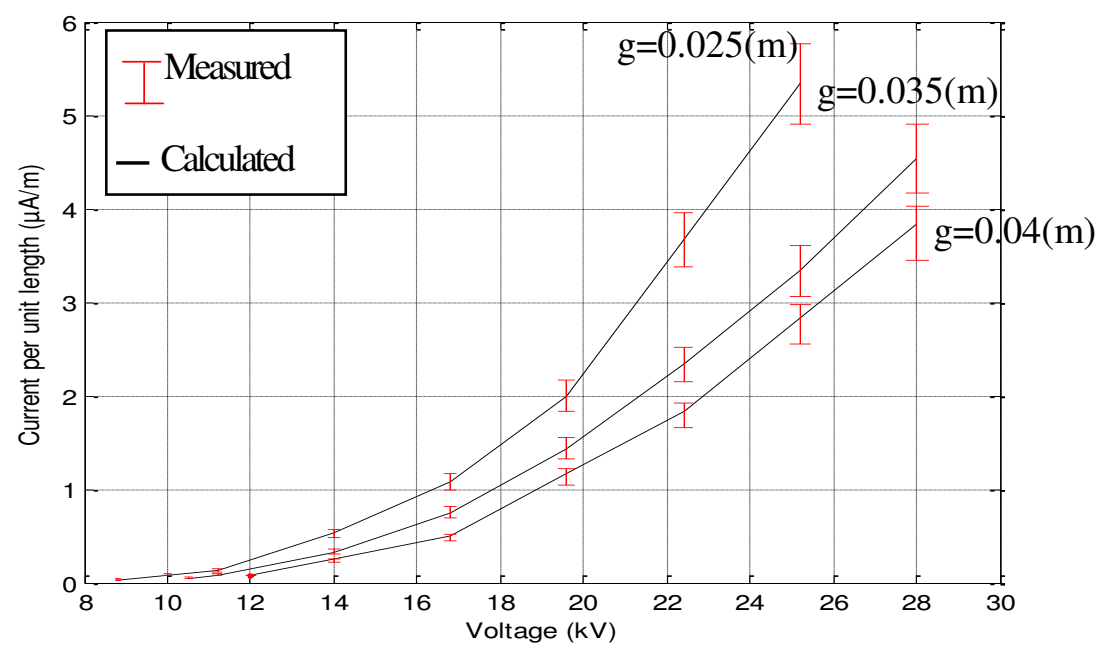

Fig. 7. Measured and calculated corona current of different gaps spacing ( $N=2-$ electrodes) ESM. 
Fahd Diab et al., Analysis of Corona Discharge in Electrostatic Motor Gaps, pp. 1842 - 1856

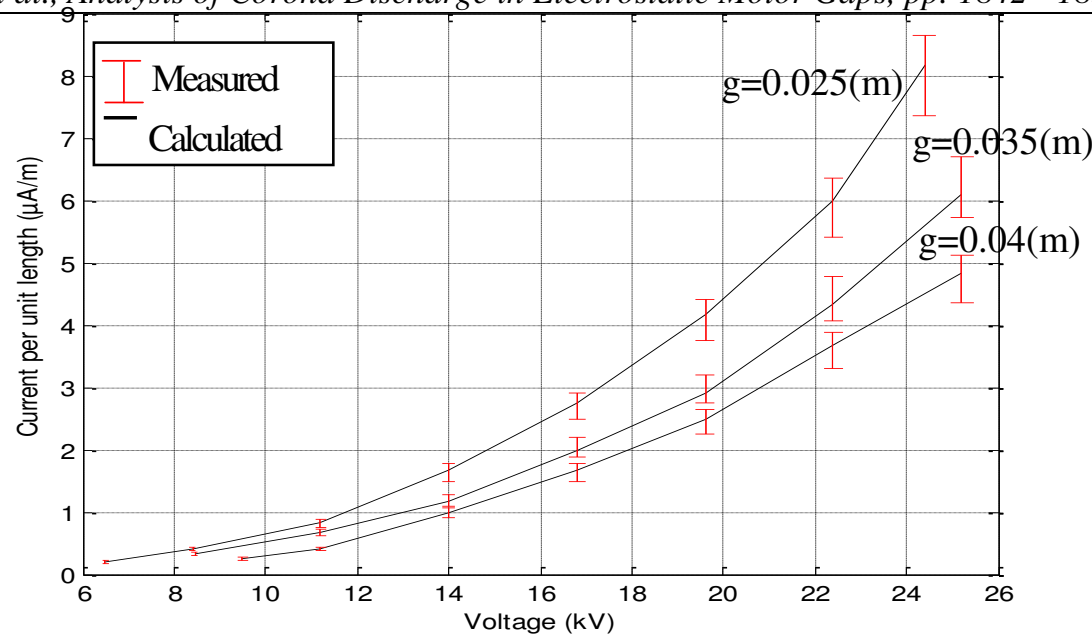

Fig. 8. Measured and calculated corona current of different gaps spacing ( $N=4$ electrodes) ESM

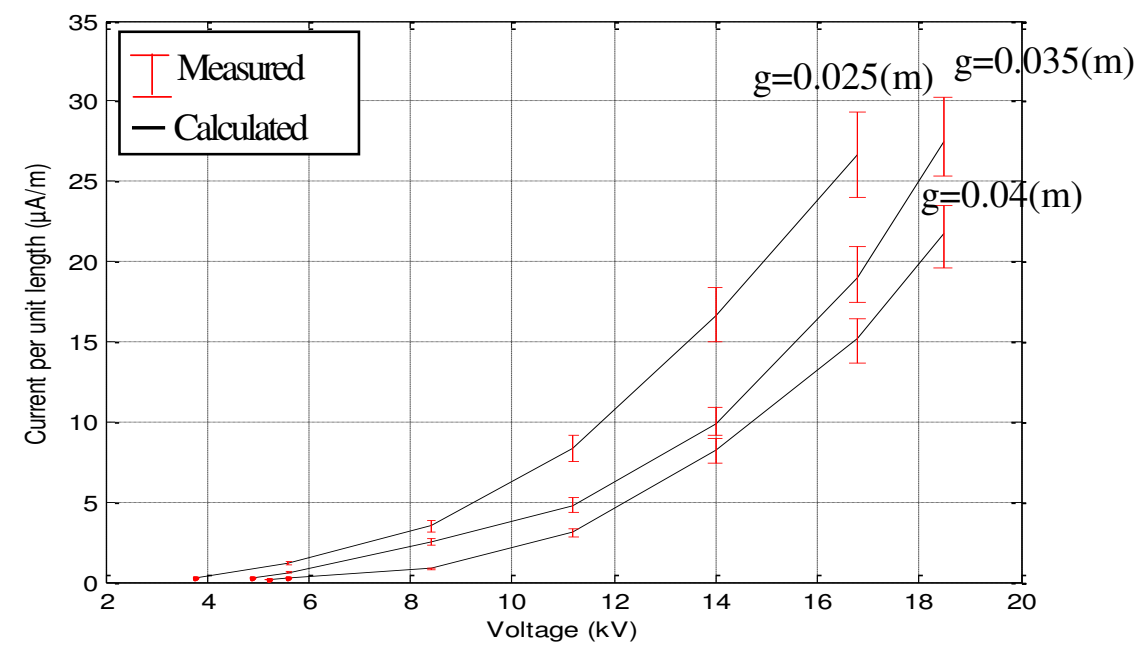

Fig. 9. Measured and calculated corona current of different gaps spacing ( $N=8$ electrodes) ESM.

Journal of Engineering Sciences, Assiut University, Faculty of Engineering, Vol. 41, No. 5, September, 2013, E-mail address: jes@aun.edu.eg 
Figures (4-9) show how the corona current per unit length of the proposed ESM changes with the applied voltage for different gap spacings and different numbers of stator electrodes. The scatter of the measured values of the corona current is also shown in figures (4-9). It is quite clear that the calculated and measured corona currents increase with the increase of number of stator electrodes irrespective of the gap spacing between the stator electrodes and rotor surface, as shown in figures (4-6). This is attributed to the increase of the electric field at the tip of stator electrodes with the increase of the number of stator electrodes with a subsequent increase of the corona current at the same value of applied voltage.

The calculated and measured corona currents increase with the decrease of the gap spacing between the stator electrodes and rotor surface irrespective of the number of stator electrodes, as shown in figures (7-9). This is attributed to the increase of the electric field at the tip of stator electrodes with the decrease of the gap spacing with a subsequent increase of the corona current at the same value of applied voltage. Figures (4-9) show a good agreement of the measured current-voltage characteristics with those calculated.

\section{Conclusions}

On the basis of the analysis presented in this paper, the following conclusions may be drawn:

1- A new design of a corona-discharge based electrostatic motor with a cylindrical rotor made from aluminum foil and multi strip stator electrodes from copper is proposed. The stator electrodes are 2, 4 and 8 in number and alternately stressed positively and negatively.

2- The spatial distribution of electric field for field mapping within the motor volume is determined using the accurate charge simulation technique.

3- The corona currents emitted from the positively and negatively-stressed electrodes are calculated being dependent on the applied voltage and motor geometry. The calculated current-voltage characteristics of the motor agreed reasonably with those measured experimentally for three motors built-in the laboratory.

\section{Symbols}
E electric field in presence of space charge.I
e electron charge.
E' space-charge-free field.
$\mathrm{E}_{\mathrm{smono}} \quad$ electric field at electrode surface where monopolar corona takes place.
$\mathrm{E}_{\mathrm{sbi}} \quad$ electric field at electrode surface where bipolar corona takes place.
g gap spacing between the stator tip and the rotor surface.
h height of wedge-shaped tip of the stator electrode.
$\mathrm{H} \quad$ total height of stator electrode.
$\mathrm{I}_{\text {monopolax }}$ monopolar corona current.
$\mathrm{I}_{\text {bipolar }}$ bipolar corona current.

Journal of Engineering Sciences, Assiut University, Faculty of Engineering, Vol. 41, No. 5, September, 2013, E-mail address: jes@aun.edu.eg 


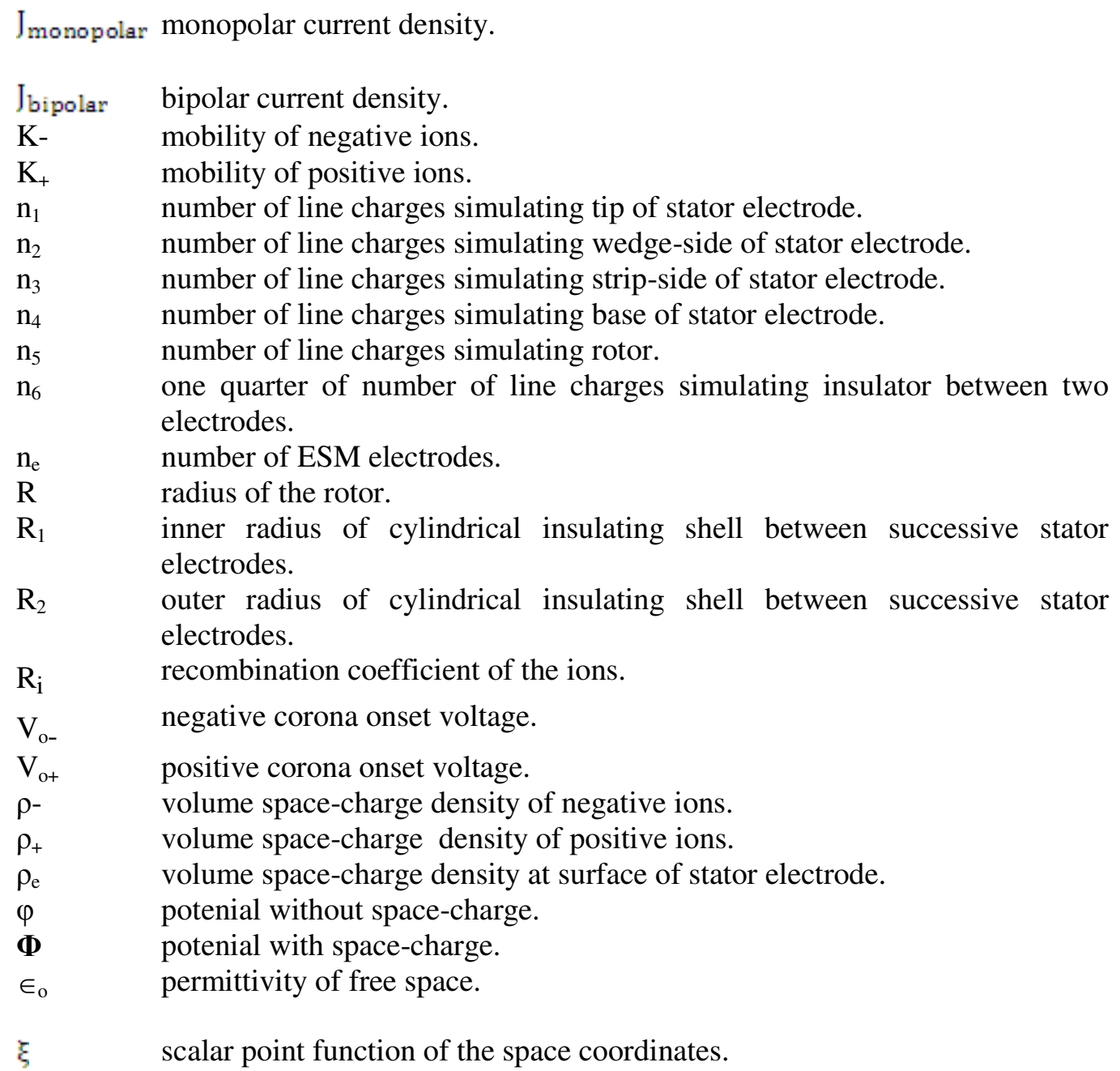

\section{References}

[1] Hattori M, Asano K and Higashiyama Y 1992 The fundamental characteristics of a cylindrical corona motor with multi-blade electrodes J. Electrostat. 27 223-35.

[2] Lee S, Kim D, Bryant M D and Ling F F 2005 A micro corona motor J. Sens. Actuators A 118 226-32.

[3] Krein P T 1995 Analysis of corona motors and micro motors by means of effective gap conductivity IEEE Trans. on Ind. Appl. 31 NO. 4 752-60.

[4] Rickard M, Rankin D D, Weinberg F and Carleton F 2005 Characterization of ionic wind velocity J. Electrostat. 63 711-6.

[5] Vatazhin A B, Likhter V A and Ulybyshev K E 2012 "Ion wind", a gas-dynamic flow in the corona discharge and its interaction with the external flow J. Fluid Dynamics 47 No. 2 206-13.

[6] Jefimenko O D 1973 Electrostatic Motors (Electret Scientific Company, Morgantown, West Virginia) pp 56-72.

Journal of Engineering Sciences, Assiut University, Faculty of Engineering, Vol. 41, No. 5, September, 2013, E-mail address: jes@aun.edu.eg 
Fahd Diab et al., Analysis of Corona Discharge in Electrostatic Motor Gaps, pp. 1842 - 1856

[7] Mizeraczyk J, Kocik M, Dekowski J, Dors M, Podlinski J, Ohkubo T, Kanazawa S and Kawasaki T 2001 Measurements of the velocity field of the flue gas flow in an electrostatic precipitator model using PIV method J. Electrostat. 51-52 272-7.

[8] Martins A A and Pinheiro M J 2011 Modeling of an EHD corona flow in nitrogen gas using an asymmetric capacitor for propulsion J. Electrostat. 69 133-8.

[9] Sakakibara et al. 1987 Air cleaner using ionic wind United States Patent No. 4643745.

[10] Martins A A 2013 Modelling of an improved positive corona thruster and actuator J. Electrostat. 71 61-7.

[11] Kalman H and Sher E 2001 Enhancement of heat transfer by means of a corona wind created by a wire electrode and confined wings assembly J. Appl. Thermal Eng. 21 265-82.

[12] Sarma M P And Janischewskyj W 1969 Analysis of corona losses on dc transmission lines IEEE Trans. on Power App. and Sys. 88 No. 5 718-31.

[13] Sarma M P And Janischewskyj W 1969 Analysis of corona losses on dc transmission lines part II-bipolar lines IEEE Trans. on Power App. and Sys. 88 1476-91.

[14] Abdel-Salam M, Anis H, Morshedy A E and Radwan R 2000 High Voltage Engineering Theory and Practice (Marcel Dekker, Inc., New York, USA) pp 9-80.

[15] Singer H, Steinbigler H and Weiss P 1973 A charge simulation method for the calculation of high voltage fields IEEE Trans. on Power App. and Sys. 93 1660-8.

[16] Ziedan H, Sayed A, Mizuno A and Ahmed A 2010 Onset voltage of corona discharge in wire-duct electrostatic precipitators IJPEST 4 No.1 36-44.

\section{تحليل التفريغ الهالى فى فجوات الموتور الاكتروستاتيكي}

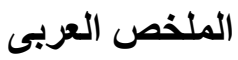

تهدف هذه المقالة الى حساب العلاقة بين تيار التفريغ الهالى والجهد المسلط على موتور الكتروستاتيكى مكون

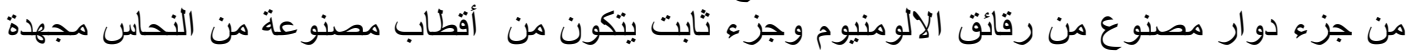

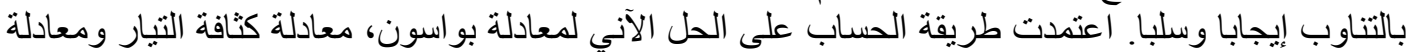

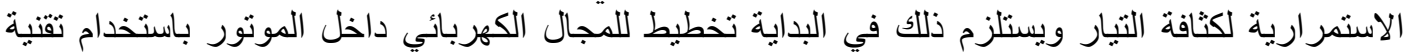

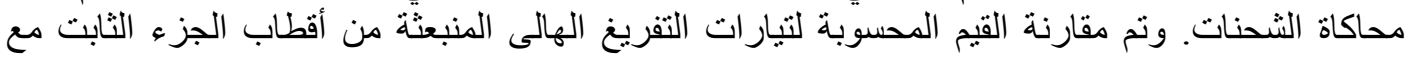

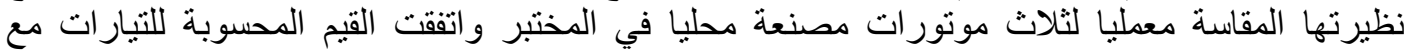
نظيرتها المقاسة معمليا.

Journal of Engineering Sciences, Assiut University, Faculty of Engineering, Vol. 41, No. 5, September, 2013, E-mail address: jes@aun.edu.eg 